\title{
2019 update of the EULAR recommendations for the management of systemic lupus erythematosus
}

\author{
Antonis Fanouriakis, ${ }^{\oplus 1}$ Myrto Kostopoulou, ${ }^{2}$ Alessia Alunno, ${ }^{3}$ Martin Aringer, ${ }^{4}$ \\ Ingeborg Bajema, ${ }^{5}$ John N Boletis, ${ }^{6}$ Ricard Cervera, ${ }^{7}$ Andrea Doria, ${ }^{\bullet} 8$ \\ Caroline Gordon, ${ }^{9}$ Marcello Govoni, ${ }^{10}$ Frédéric Houssiau, ${ }^{11}$ David Jayne, ${ }^{12}$ \\ Marios Kouloumas, ${ }^{13}$ Annegret Kuhn, ${ }^{14}$ Janni L Larsen, ${ }^{15}$ Kirsten Lerstrøm, ${ }^{16}$ \\ Gabriella Moroni, ${ }^{17}$ Marta Mosca, ${ }^{18}$ Matthias Schneider, ${ }^{19}$ Josef S Smolen, $^{20}$ \\ Elisabet Svenungsson, ${ }^{21}$ Vladimir Tesar, ${ }^{22}$ Angela Tincani, ${ }^{23}$ Anne Troldborg, ${ }^{24}$ \\ Ronald van Vollenhoven, ${ }^{25}$ Jörg Wenzel, ${ }^{26}$ George Bertsias, ${ }^{27}$ Dimitrios T Boumpas ${ }^{1,28,29}$
}

\section{Handling editor David S Pisetsky}

- Additional material is published online only. To view please visit the journal online (http://dx.doi.org/10.1136/ annrheumdis-2019-215089).

For numbered affiliations see end of article.

\section{Correspondence to} Dr Antonis Fanouriakis, Rheumatology and Clinical Immunology Unit, "Attikon" University Hospital, Athens

12462, Greece;

afanour@med.uoa.gr

GB and DTB contributed equally.

Received 18 January 2019 Revised 7 March 2019 Accepted 11 March 2019 Published Online First 29 March 2019

\section{ABSTRACT}

Our objective was to update the EULAR

recommendations for the management of systemic lupus erythematosus (SLE), based on emerging new evidence. We performed a systematic literature review (01/2007-12/2017), followed by modified Delphi method, to form questions, elicit expert opinions and reach consensus. Treatment in SLE aims at remission or low disease activity and prevention of flares. Hydroxychloroquine is recommended in all patients with lupus, at a dose not exceeding $5 \mathrm{mg} / \mathrm{kg}$ real body weight. During chronic maintenance treatment, glucocorticoids (GC) should be minimised to less than $7.5 \mathrm{mg} /$ day (prednisone equivalent) and, when possible, withdrawn. Appropriate initiation of immunomodulatory agents (methotrexate, azathioprine, mycophenolate) can expedite the tapering/discontinuation of GC. In persistently active or flaring extrarenal disease, add-on belimumab should be considered; rituximab (RTX) may be considered in organ-threatening, refractory disease. Updated specific recommendations are also provided for cutaneous, neuropsychiatric, haematological and renal disease. Patients with SLE should be assessed for their antiphospholipid antibody status, infectious and cardiovascular diseases risk profile and preventative strategies be tailored accordingly. The updated recommendations provide physicians and patients with updated consensus guidance on the management of SLE, combining evidence-base and expert-opinion.

\section{INTRODUCTION}

Systemic lupus erythematosus (SLE) has variable presentation, course and prognosis. The wide acceptance and popularity of the first EULAR recommendations for its management, published in $2008,{ }^{1}$ prompted the subsequent development of specific recommendations regarding monitoring, neuropsychiatric and renal disease, as well as for pregnancy and women's health in lupus. ${ }^{2-5}$ Since these publications, new data have emerged on treatment strategies and validated goals of treatment, alternative regimens of glucocorticoids (GC), 'multitargeted' therapy with the use of calcineurin inhibitors (CNIs) in lupus nephritis (LN), and the approval of the first biological therapy for SLE. These advances called for an update of the EULAR recommendations for lupus, capitalising on the strengths of and experience from the previous projects. ${ }^{6}$

\section{METHODS}

After approval by the EULAR Executive Committee, the convenor (DB) and methodologist (GB) invited a Task Force to work on this update; two fellows (AF, MK) undertook the systematic literature review (SLR). The EULAR standardised operating procedures ${ }^{7}$ and the Appraisal of Guidelines Research and Evaluation instrument (AGREE II) ${ }^{8}$ were followed. Applying a Delphi-based methodology, 14 research questions were selected for SLR (online supplementary table 1). PubMed was screened using strings of relevant terms. Since this was an update of the previous 2007 recommendations, the SLR considered all English-language publications from 01/2007 until 12/2017, with two exceptions: (1) treatment of skin disease, where an unrestricted date search was performed and (2) renal disease, where search was limited to the period 01/2012-12/2017 (since the EULAR recommendations for $\mathrm{LN}$ were published in 2012). Pertinent articles, identified by manual search within the reference list of the originally retrieved publications, were also included. All retrieved items were refined based on article type, abstract, full-text content and number of included patients. The final level of evidence and grading of recommendations considered also the body of evidence that had informed the previous sets of EULAR recommendations for the management of SLE, as the convenor, methodologist and several of the panellists had also participated in the latter. A detailed presentation of the SLR results is given in online supplementary tables 2 and 3. Evidence was categorised based on the design and validity of available studies and the strength of the statements was graded (see online supplementary table 4). After rounds of discussions, the committee reached a consensus of 33 final statements, grouped in four broad categories (Goals of Treatment, Treatment of SLE, Specific manifestations, Comorbidities-table 1). Each Task Force member rated their agreement with each statement. 
Table 1 Recommendations for the management of patients with systemic lupus erythematosus

\section{Overarching principles}

- SLE is a multisystem disease - occasionally limited to one or few organs_-diagnosed on clinical grounds in the presence of characteristic serological abnormalities.

- SLE care is multidisciplinary, based on a shared patient-physician decision, and should consider individual, medical and societal costs.

- Treatment of organ-threatening/life-threatening SLE includes an initial period of high-intensity immunosuppressive therapy to control disease activity, followed by a longer period of less intensive therapy to consolidate response and prevent relapses.

Treatment goals include long-term patient survival, prevention of organ damage and optimisation of health-related quality of life.

Recommendation/Statement

Level of agreement,

1. Goals of treatment mean (SD)

1.1 Treatment in SLE should aim at remission or low disease activity ( $2 \mathrm{~b} / \mathbf{B})$ and prevention of flares ( $2 \mathrm{~b} / \mathbf{B})$ in all organs, maintained with the lowest possible dose 10.0 (0) of glucocorticoids.

1.2 Flares of SLE can be treated according to the severity of organ(s) involvement by adjusting ongoing therapies (glucocorticoids, immunomodulating agents) to 9.95 ( 0.22 ) higher doses, switching or adding new therapies $(2 \mathrm{~b} / \mathrm{C})$.

2. Treatment of SLE

2.1 HCQ

2.1.1 HCQ is recommended for all patients with SLE (1b/A), unless contraindicated, at a dose not exceeding $5 \mathrm{mg} / \mathrm{kg} / \mathrm{real} \mathrm{BW}(3 \mathrm{~b} / \mathrm{C})$.

2.1.2 In the absence of risk factors for retinal toxicity, ophthalmological screening (by visual fields examination and/or spectral domain-optical coherence

tomography) should be performed at baseline, after 5 years, and yearly thereafter ( $2 \mathrm{~b} / \mathrm{B})$.

$2.2 \mathrm{GC}$

2.2.1 GC can be used at doses and route of administration that depend on the type and severity of organ involvement ( $2 \mathrm{~b} / \mathrm{C})$.

2.2.2 Pulses of intravenous methylprednisolone (usually 250-1000 mg per day, for 1-3 days) provide immediate therapeutic effect and enable the use of lower starting dose of oral GC (3b/C).

2.2.3 For chronic maintenance treatment, GC should be minimised to less than $7.5 \mathrm{mg} /$ day (prednisone equivalent) (1 b/B) and, when possible, withdrawn.

2.2.4 Prompt initiation of immunomodulatory agents can expedite the tapering/discontinuation of GC (2b/B)

2.3 Immunosuppressive therapies

2.3.1 In patients not responding to HCQ (alone or in combination with GC) or patients unable to reduce GC below doses acceptable for chronic use, addition of immunomodulating/immunosuppressive agents such as methotrexate, (1b/B) azathioprine ( $2 \mathrm{~b} / \mathrm{C})$ or mycophenolate (2a/B) should be considered.

2.3.2 Immunomodulating/immunosuppressive agents can be included in the initial therapy in cases of organ-threatening disease ( $2 \mathrm{~b} / \mathrm{C})$.

2.3.3 Cyclophosphamide can be used for severe organ-threatening or life-threatening SLE as well as 'rescue' therapy in patients not responding to other

immunosuppressive agents $(2 \mathrm{~b} / \mathrm{C})$

2.4 Biologics

2.4.1 In patients with inadequate response to standard-of-care (combinations of HCQ and GC with or without immunosuppressive agents), defined as residual disease activity not allowing tapering of glucocorticoids and/or frequent relapses, add-on treatment with belimumab should be considered (1a/A).

2.4.2 In organ-threatening disease refractory or with intolerance/contraindications to standard immunosuppressive agents, rituximab can be considered ( $2 \mathrm{~b} / \mathrm{C}$ ).

$9.20(0.81)$

3 Specific manifestations

3.1 Skin disease

3.1.1 First-line treatment of skin disease in SLE includes topical agents (GC, calcineurin inhibitors) (2b/B), antimalarials (HCQ, quinacrine) (1a/A) and/or systemic GC $(4 / C)$.

3.1.2 In non-responsive cases or cases requiring high-dose GC, methotrexate (3a/B), retinoids (4/C), dapsone (4/C) or mycophenolate (4/C) can be added.

$10.0(0)$

3.2 Neuropsychiatric disease

3.2.1 Attribution to SLE - as opposed to non-SLE-related neuropsychiatric manifestations, is essential and can be facilitated by neuroimaging, investigation of cerebrospinal fluid, consideration of risk factors (type and timing of the manifestation in relation to the onset of lupus, patient age, non-neurological lupus activity, presence of $\mathrm{aPL}$ ) and exclusion of confounding factors $(2 \mathrm{~b} / \mathrm{C})$.

3.2.2 Treatment of SLE-related neuropsychiatric disease includes glucocorticoids/immunosuppressive agents for manifestations considered to reflect an inflammatory process (1b/A), and antiplatelet/anticoagulants for atherothrombotic/aPL-related manifestations (2b/C).

$9.85(0.48)$

3.3 Haematological disease

3.3.1 Acute treatment of lupus thrombocytopenia includes high-dose GC (including pulses of intravenous methylprednisolone) (4/C) and/or intravenous immunoglobulin $\mathrm{G}(\mathbf{4} / \mathrm{C})$.

3.3.2 For maintenance of response, immunosuppressive/GC-sparing agents such as mycophenolate ( $2 \mathrm{~b} / \mathrm{C})$, azathioprine ( $2 \mathrm{~b} / \mathrm{C})$ or cyclosporine $(4 / \mathrm{C})$ can be used. 9.75 (0.62)

3.3.3 Refractory cases can be treated with rituximab (3a/C) or cyclophosphamide (4/C).

3.4 Renal disease

3.4.1 Early recognition of signs of renal involvement and—when present-performance of a diagnostic renal biopsy are essential to ensure optimal outcomes $(2 \mathrm{~b} / \mathrm{B})$.

3.4.2 Mycophenolate (1a/A) or low-dose intravenous cyclophosphamide ( $2 \mathrm{a} / \mathbf{B})$ are recommended as initial (induction) treatment, as they have the best efficacyl 9.85 (0.36) toxicity ratio.

3.4.3 In patients at high risk for renal failure (reduced glomerular filtration rate, histological presence of fibrous crescents or fibrinoid necrosis, or tubular atrophy/ 9.45 ( 0.80 ) interstitial fibrosis], similar regimens may be considered but high-dose intravenous cyclophosphamide can also be used (1 $\mathbf{b} / \mathbf{A})$.

3.4.4 For maintenance therapy, mycophenolate (1a/A) or azathioprine (1a/A) should be used. 
3.4.5 In cases with stable/improved renal function but incomplete renal response (persistent proteinuria $>0.8-1 \mathrm{~g} / 24$ hours after at least 1 year of

4.1.2 Patients with SLE with high-risk aPL profile (persistently positive medium/high titres or multiple positivity) may receive primary prophylaxis with antiplatelet 9.45 (0.80) agents $(2 \mathrm{a} / \mathrm{C})$, especially if other atherosclerotic/thrombophilic factors are present, after balancing the bleeding hazard.

4.1.3 For secondary prevention (thrombosis, pregnancy complication/loss), the therapeutic approach should be the same as for primary antiphospholipid

4.3.1 Patients with SLE should undergo regular assessment for traditional (1 b/B-C) and disease-related risk factors for cardiovascular disease, including persistently active disease (1b/B), increased disease duration (1b/A), medium/high titres of aPL (1 b/A), renal involvement (1 b/B) (especially, persistent proteinuria and/or GFR $<60 \mathrm{~mL} / \mathrm{min}$ ) and chronic use of GC (1 b/B).

4.3.2 Based on their individual cardiovascular risk profile, patients with SLE may be candidates for preventative strategies as in the general population, including 9.85 ( 0.48 ) low-dose aspirin (2b/D) and/or lipid-lowering agents (2b/D).

aPL, antiphospholipid antibodies; GC, glucocorticoids; GFR, glomerular filtration rate; HCQ, hydroxychloroquine; SLE, systemic lupus erythematosus.

\section{RESULTS AND DISCUSSION}

\section{Overarching principles}

SLE represents a challenge for the treating physician in terms of diagnosis and treatment. Its protean manifestations, often multisystem but occasionally limited to a few or single organ, have led some physicians to focus exclusively on evidence of serological autoimmunity (antinuclear and more specific autoantibodies), for a disease where diagnosis is clinical after excluding competing diagnoses. Monitoring of SLE through validated disease activity and chronicity indices, including physician global assessment (PGA), is recommended. For patients with severe disease, multidisciplinary care in dedicated lupus centres is desirable. ${ }^{9}$ Immunosuppressive (IS) therapy (for induction and maintenance of remission) is indicated in organ-threatening lupus.

\section{Recommendations}

Goals of treatment

To improve long-term patient outcomes, management should aim at remission of disease symptoms and signs, prevention of damage accrual and minimisation of drug side-effects, as well as improvement of quality of life. ${ }^{10} 11$ Complete remission (absence of clinical activity with no use of GC and IS drugs) is infrequent. $^{12-16}$ To this end, newly defined low disease activity states (based on a SLEDAI score $\leq 3$ on antimalarials, or alternatively SLEDAI $\leq 4$, PGA $\leq 1$ with GC $\leq 7.5 \mathrm{mg}$ of prednisone and well tolerated IS agents) have shown comparable rates with remission, regarding halting of damage accrual (OR 0.5-0.7 for increase in damage index) and prevention of flares. ${ }^{14}$ 17-20 Accordingly, treatment in SLE should aim at remission or, if this state cannot be achieved, at low disease activity in all organ systems. In LN, therapy should aim at least partial remission (defined as $\geq 50 \%$ reduction in proteinuria [UPr] to subnephrotic levels and serum creatinine [SCr] within 10\% from baseline) by 6-12 months; complete renal remission (proteinuria $<500 \mathrm{mg} / 24$ hours and SCr within 10\% from baseline), however, may require longer treatment duration, often more than 12 and until 24 months.
In monitoring renal response, reduction of UPr (to less than $0.8 \mathrm{~g} /$ day) following treatment is more important than residual haematuria. ${ }^{21}$ Patients with more severe proteinuria and longerstanding disease are less likely to respond or show more delayed responses. $^{22} 23$

Prevention of disease flares is an additional milestone of SLE treatment. Although a universally accepted definition is lacking, most experts agree that a flare is a measurable increase in disease activity usually leading to change of treatment. ${ }^{24}$ Flares are common in the disease course and contribute significantly to organ damage accrual and worse outcome. ${ }^{172526}$ Consistently reported risk factors for a higher disease flare rate include younger age at disease onset, no use of antimalarials, persistent generalised disease activity and serological activity (anti-dsDNA, low complement). ${ }^{27-31}$ Assessment of adherence to drug treatment, close monitoring and optimisation of disease control in these patients may reduce the risk for a flare.

\section{Treatment of SLE} Hydroxychloroquine

Hydroxychloroquine (HCQ) is recommended for all patients with SLE. There is evidence for multiple beneficial effects of HCQ in SLE, ${ }^{32}$ yet poor adherence to treatment is not uncommon. ${ }^{33-35}$ Drug blood levels can be used to assess compliance, ${ }^{33} 35$ but data are currently insufficient to recommend routine monitoring of drug levels. Concerns for retinal toxicity with long-term HCQ therapy led to the use of more sensitive screening techniques, with a prevalence of retinal abnormalities exceeding 10\% after 20 years of continuous use. ${ }^{3637}$ Major risk factors for retinopathy include duration of treatment (OR 4.71 for every 5 years of use), dose (OR 3.34 for every $100 \mathrm{mg}$ daily dose), chronic kidney disease (adjusted OR 8.56) and pre-existing retinal or macular disease. ${ }^{37}$ Based on existing evidence suggesting that the risk of toxicity is very low for doses below $5 \mathrm{mg} / \mathrm{kg}$ real body weight, the daily dose should not exceed this threshold. Of note, efficacy of HCQ in lupus has been established in studies 
with a prescribed dose of $6.5 \mathrm{mg} / \mathrm{kg} /$ day, thus it remains to be confirmed whether a lower dose will have comparable clinical effects. Patients in long-standing remission may have their dose lowered, although no studies have formally addressed this strategy. The choice of quinacrine, an alternative antimalarial, can be considered in patients with cutaneous manifestations and HCQ-induced retinal toxicity.

\section{Glucocorticoids}

GC can provide rapid symptom relief, but the medium to longterm aim should be to minimise daily dose to $\leq 7.5 \mathrm{mg} / \mathrm{day}$ prednisone equivalent or to discontinue them, because longterm GC therapy can have various detrimental effects including irreversible organ damage. ${ }^{38-41}$ Risks are substantially increased at continuous GC doses above $7.5 \mathrm{mg} /$ day, with some studies suggesting that also lower doses might be harmful. ${ }^{172-44}$ To this end, two approaches can be considered: (1) use of pulses of intravenous methylprednisolone (MP) of various doses (depending on severity and body weight), which take advantage of the rapid non-genomic effects of $\mathrm{GC}^{45}$ and may allow for a lower starting dose and faster tapering of PO GC, ${ }^{46} 47$ and (2) early initiation of IS agents, to facilitate tapering and eventual discontinuation of oral GC (see below). High-dose intravenous MP (usually $250-1000 \mathrm{mg} /$ day for 3 days) is often used in acute, organ-threatening disease (eg, renal, neuropsychiatric) after excluding infections. ${ }^{48}$

\section{Immunosuppressive (IS) drugs}

Consequent initiation of IS drugs facilitates a more rapid GC tapering and may prevent disease flares. ${ }^{49}$ The choice of agent depends on prevailing disease manifestation(s), patient age and childbearing potential, safety concerns and cost. Methotrexate (MTX) and azathioprine (AZA) should be considered in patients with poor symptom control after a trial with GC and HCQ or when HCQ alone is unlikely to be sufficient, due to the large experience gained with their use and their relatively safe profile. ${ }^{50}$ Published evidence is generally stronger for MTX than AZA, yet the latter is compatible with pregnancy contemplation. Mycophenolate mofetil (MMF) is a potent immunosuppressant with efficacy in renal and non-renal lupus (although not in neuropsychiatric disease). ${ }^{51-53}$ In a recent randomised, open-label trial in extrarenal SLE, enteric-coated mycophenolate sodium (EC-MPS) was superior to AZA in achieving remission and reducing flares. ${ }^{54}$ However, its teratogenic potential (needs to be discontinued at least 6 weeks before conceiving), along with its higher cost compared with AZA or MTX, poses a limitation towards universal recommendation in women of reproductive age with non-renal manifestations. Cyclophosphamide (CYC) can be considered in organ-threatening disease (especially renal, cardiopulmonary or neuropsychiatric) and only as rescue therapy in refractory non-major organ manifestations; due to its gonadotoxic effects, it should be used with caution in women and men of fertile age. ${ }^{55-57}$ Concomitant use of GnRH analogues attenuates the depletion of ovarian reserve associated with CYC therapy and is recommended in premenopausal patients with SLE. ${ }^{458}{ }^{59}$ Information about the possibility of ovarian cryopreservation should be offered ahead of treatment. Other risks of CYC therapy such as malignancy and infections should also be considered. ${ }^{60} 61$

\section{Biological agents}

There is evidence to support beneficial effects of B-cell targeting agents in SLE. ${ }^{62-66}$ Belimumab should be considered in extrarenal disease with inadequate control (ongoing disease activity or frequent flares) to first-line treatments (typically including combination of HCQ and prednisone with or without IS agents), and inability to taper GC daily dose to acceptable levels (ie, maximum $7.5 \mathrm{mg} /$ day). Patients with persistent disease may benefit from belimumab; more likely to respond are patients with high disease activity (eg, SLEDAI $>10$ ), prednisone dose $>7.5 \mathrm{mg} /$ day and serological activity (low C3/C4, high antidsDNA titres), with cutaneous, musculoskeletal and serological manifestations responding the most. ${ }^{67-69}$

Due to the negative results of randomised controlled trials (RCTs), RTX is currently only used off-label, in patients with severe renal or extrarenal (mainly haematological and neuropsychiatric) disease refractory to other IS agents and/or belimumab, or in patients with contraindications to these drugs. As a general rule, more than one IS drug need to have failed prior to RTX administration, ${ }^{70-73}$ except perhaps for cases of severe autoimmune thrombocytopaenia and haemolytic anaemia, where RTX has demonstrated efficacy both in lupus and in patients with isolated immune thrombocytopaenia (ITP). ${ }^{74-76}$ In LN, RTX is typically considered following failure of first-line therapies (CYC, MMF) or in relapsing disease. ${ }^{70} 77$ More recently, a posthoc analysis of the LUNAR trial showed that complete B-cell depletion following RTX treatment in LN was associated with higher odds for complete response at 78 weeks. ${ }^{78}$

Figure 1 summarises the various drugs used in the treatment of SLE, according to disease severity stratification. Online supplementary table 5 outlines the recommended doses of the drugs mentioned in the manuscript.

\section{Specific manifestations \\ Skin disease}

A large body of evidence originates from studies in patients with cutaneous lupus erythematosus (CLE). Effective protection from ultraviolet exposure with broad-spectrum sunscreens and smoking cessation are strongly recommended. ${ }^{79-81}$ In atypical or refractory cases, a diagnostic skin biopsy should be considered. First-line treatment of skin disease includes topical agents (GC and/or CNIs) and antimalarials, with or without systemic GC (the latter at a starting dose depending on severity of skin involvement). ${ }^{82} \mathrm{HCQ}$ is the antimalarial of choice over chloroquine due to its multiple beneficial effects and possibly lower risk for retinal toxicity $;^{84}$ in cases of inadequate response or evidence of toxic retinopathy, quinacrine (mepacrine) may be used as an add-on or sequential therapy, respectively. ${ }^{85-87}$ Although quinacrine is currently unavailable in several countries worldwide, it is a useful alternative when available. There are no studies examining retinal toxicity of quinacrine with the newer, more sensitive screening techniques (visual fields or optical coherence tomography); however with current knowledge, retinopathy is not considered a side-effect of quinacrine.

A sizeable proportion (almost 40\%) of patients will not respond to first-line treatment. ${ }^{868}$ In such cases, MTX can be added. $^{50} 89$ Other agents include retinoids, dapsone and MMF or EC-mycophenolic acid. ${ }^{79} 9091$ Belimumab and RTX have also shown efficacy in mucocutaneous manifestations of SLE, although these studies have not included a validated activity score for skin lesions; RTX may be less efficacious in chronic forms of skin lupus. ${ }^{62}{ }^{92-94}$ Thalidomide is effective in various subtypes of cutaneous disease. ${ }^{95} 96$ Due to its strict contraindication in pregnancy, the risk for irreversible polyneuropathy, and the frequent relapses on drug discontinuation, it should be considered only as a 'rescue' therapy in patients who have failed 


\section{Treatment of non-renal Systemic Lupus Erythematosus}

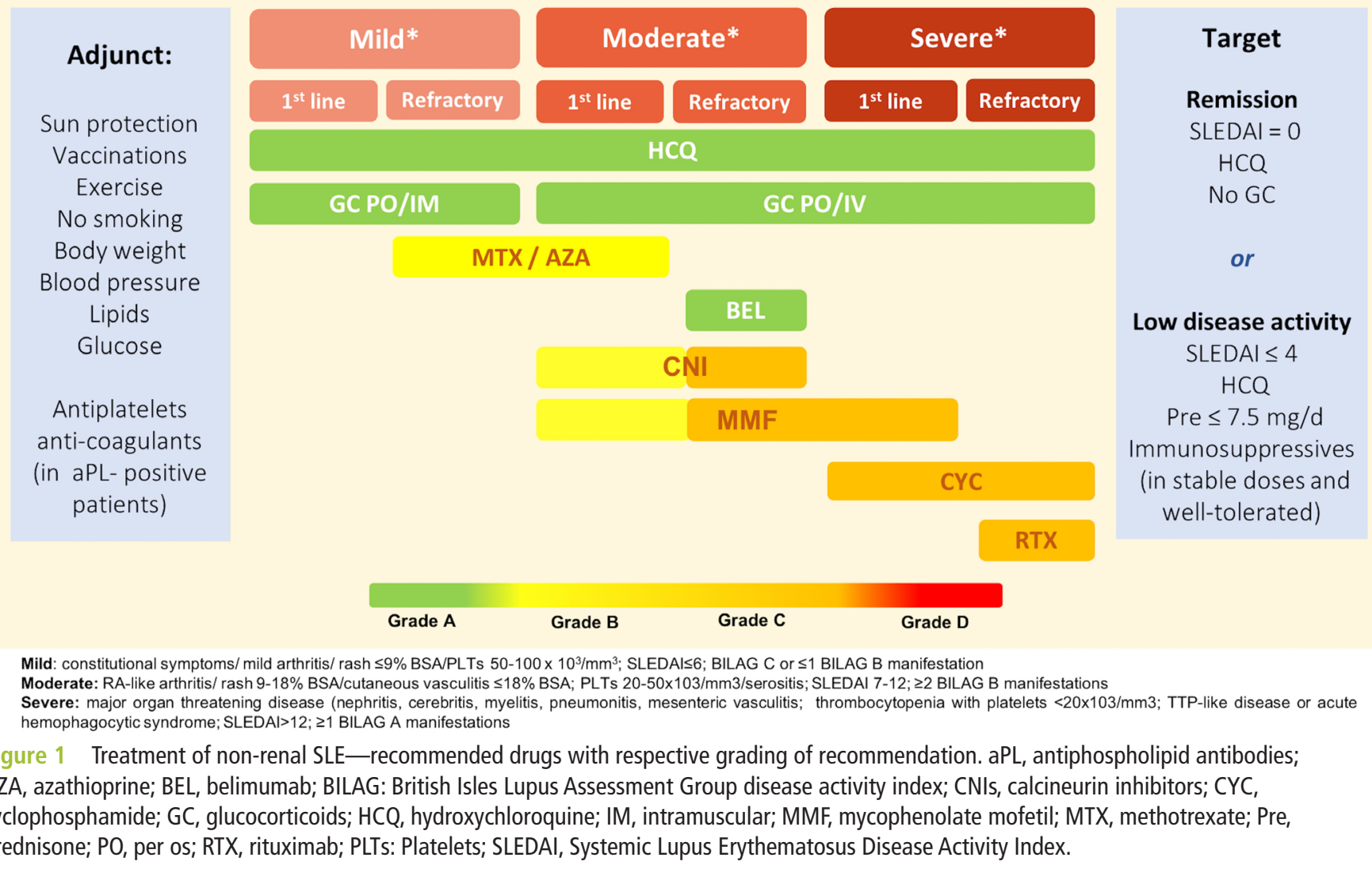

multiple previous agents. A treatment algorithm for the various subtypes of CLE has been published by a European group of Dermatologists guided by the European Dermatology Forum in cooperation with the European Academy of Dermatology and Venereology. ${ }^{79}$

\section{Neuropsychiatric disease (NPSLE)}

Attribution of neuropsychiatric manifestations to SLE often requires a comprehensive, multidisciplinary approach to rule out mimics (infections, malignancy and others), taking into account the presence of risk ('favouring') factors (type and timing of manifestation, presence of generalised, non-neurological disease activity, abnormal neuroimaging and cerebrospinal fluid analysis, positive antiphospholipid antibodies [aPL]), ${ }^{97}$ as well as confounding factors favouring alternative diagnoses. ${ }^{98}$ The use of validated attribution models may aid in the diagnostic process. $^{99} 100$

Treatment of NPSLE depends on whether the underlying pathophysiological mechanism is presumed to be inflammatory or embolic/thrombotic/ischaemic. ${ }^{2101} \mathrm{GC}$ and/or IS agents should be considered in the former, while anticoagulant/antithrombotic treatment is favoured when aPL antibodies are present. $^{102-107}$ Distinction between the two pathophysiological processes may not be easy in clinical practice, or the two processes may coexist in the same patient. ${ }^{2}$ Combination of IS and anticoagulant/antithrombotic therapy may be considered in these patients. Patients with SLE with cerebrovascular disease should be managed like the general population in the acute phase; in addition to controlling extra-CNS lupus activity, IS therapy may be considered in the absence of aPL antibodies and other atherosclerotic risk factors or in recurrent cerebrovascular events. ${ }^{108}$ In this context, neuroimaging and/or CSF studies may provide additional supporting evidence for IS therapy. Targeted symptomatic therapy is indicated according to the type of manifestation (eg, antipsychotics for psychosis, anxiolytics for anxiety disorder and so on).

\section{Haematological disease}

Haematological manifestations frequently necessitating anti-inflammatory/IS treatment in patients with SLE include thrombocytopaenia and autoimmune haemolytic anaemia (AIHA). First-line treatment of significant lupus thrombocytopaenia (platelet count below $30000 / \mathrm{mm}^{3}$ ) consists of moderate/high doses of GC in combination with IS agent (AZA, MMF or cyclosporine; the latter having the least potential for myelotoxicity) to facilitate GC-sparing. Initial therapy with pulses of intravenous MP (1-3 days) is encouraged. Intravenous immunoglobulin (IVIG) may be considered in the acute phase, in cases of inadequate response to high-dose GC or to avoid GC-related infectious complications.

Treatment of thrombocytopenia is typically lengthy and often characterised by relapses during GC tapering. ${ }^{109}$ In patients with no response to GC (ie, failure to reach a platelet count $>50000 /$ $\mathrm{mm}^{3}$ ) or relapses, RTX should be considered, considering also its efficacy in ITP. ${ }^{7476110}$ CYC may also be considered in such cases. Thrombopoietin agonists or splenectomy should be reserved as last options. ${ }^{111} 112$ Autoimmune haemolytic anaemia (AIHA) is far less common than thrombocytopenia in SLE; its treatment follows the same principles regarding use of GC, IS drugs and RTX. Autoimmune leucopaenia is common in SLE but rarely needs treatment; careful work-up is recommended to exclude other causes of leucopaenia (especially drug-induced). 


\section{Renal disease}

Patients at high risk of developing renal involvement (males, juvenile lupus onset, serologically active including positivity for anti-C1q antibodies) ${ }^{113-115}$ should be under vigilant monitoring (eg, at least every 3 months) to detect early signs of kidney disease. Following diagnosis, secured with a kidney biopsy, treatment of LN includes an initial induction phase, followed by a more prolonged maintenance phase. MMF and CYC are the IS agents of choice for induction treatment; low-dose CYC (Euro-Lupus regimen, online supplementary table 5) is preferred over highdose CYC as it has comparable efficacy and lower risk of gonadotoxicity. ${ }^{57116117}$ Published data support the use of MMF and high-dose CYC (online supplementary table 5) in severe forms of $\mathrm{LN}$ associated with increased risk of progression into end-stage renal disease (reduced glomerular filtration rate, histological presence of fibrous crescents or fibrinoid necrosis, or tubular atrophy/interstitial fibrosis). ${ }^{118} 119$ An early significant drop in $\mathrm{UPr}$ (to $\leq 1 \mathrm{~g} /$ day at 6 months or $\leq 0.8 \mathrm{~g} /$ day at 12 months) is a predictor of favourable long-term renal outcome. ${ }^{21117120} \mathrm{MMF}$ or AZA may be used as maintenance therapy, with the former associated with fewer relapses; ${ }^{121} 122$ the choice depends on the agent used for induction phase and on patient characteristics, including age, race and wish for pregnancy. In refractory or relapsing disease, RTX may be considered.

Following the EULAR recommendations for LN in 2012, several studies have been published regarding the use of CNIs to treat proliferative $\mathrm{LN}$, either alone or in the form of a 'multitarget therapy' (combination of tacrolimus with MMF). ${ }^{123-127}$ These studies were performed almost exclusively in Asian populations and had short follow-up; hence, data have to be corroborated with longer duration studies in multiethnic populations. To this end, at present, CNIs may be considered as second-line agents for induction or maintenance therapy mainly in membranous LN, podocytopathy, or in proliferative disease with refractory nephrotic syndrome, despite standard-of-care within 3-6 months; ${ }^{128} 129$ in the latter case, they may be used alone or in combination with MMF, since small, observational studies have shown the CNI/MMF combination to be effective in disease refractory to standard therapy. ${ }^{130-132}$ Monitoring SCr and blood levels of CNI to avoid chronic drug toxicity is essential.

\section{Comorbidities \\ Antiphospholipid antibodies (aPL) and antiphospholipid syndrome (APS)}

The presence of aPL is associated with thrombotic and obstetric complications and increased risk of damage accrual. ${ }^{133} 134$ In aPL carriers, a recent meta-analysis supported a protective role of low-dose aspirin for primary prophylaxis against thrombosis in the subgroup of aPL carriers who had SLE $;^{135}$ however, in view of the potential bleeding hazard, ${ }^{136137}$ it is not clear whether this should be applied to patients with lupus with any aPL antibodies or only to those carrying a high risk aPL profile (ie, triple aPL positivity, lupus anticoagulant or high titres of anticardiolipin antibodies). ${ }^{138}$ Patients with SLE with aPL may also receive additional anticoagulant treatment, such as low-molecular weight heparin, during high-risk periods for thrombosis (pregnancy or postoperatively), although no studies have formally addressed this question.

No studies have been performed exclusively on patients with SLE-APS, with several studies excluding secondary APS due to lupus. Thus, with current knowledge, treatment of APS in the context of SLE should not differ from treatment of primary APS. A recent randomised, open-label trial comparing rivaroxaban to warfarin in APS with triple aPL positivity ( $21 \%$ of patients had SLE-APS) was prematurely terminated due to an excess of thromboembolic events in the rivaroxaban arm. ${ }^{139}$ Thus, in patients with SLE-APS, use of novel oral anticoagulants for secondary prevention should be avoided; however, they could potentially serve as an alternative option in selected patients (low-risk aPL profile, no history of arterial thrombotic events) with difficult to control international normalised ratio on warfarin, after balancing possible risks.

\section{Infections}

Risk of infection in SLE is associated with both disease-related and treatment-related factors; high-dose GC therapy, CYC, MMF and RTX are all associated with an increased risk for infection, while high disease activity, severe leucopaenia and presence of renal involvement ( \pm hypogammaglobulinaemia in nephrotic syndrome) also contribute independently. ${ }^{48}$ 140-143 Protection against infections should be proactive, focusing both on primary prevention, as well as timely recognition and treatment. Patients with lupus should receive vaccinations according to the EULAR recommendations for vaccination of patients with autoimmune rheumatic diseases. ${ }^{144} 145$ Immunisation against seasonal influenza and pneumococcal infection (both PCV13 and PPSV23) should be strongly considered, preferably during stable disease. Herpes zoster vaccination is now available for the general population, but a study in SLE has not been performed. Prompt diagnosis and treatment of sepsis is essential. To this end, validated scores such as the quick SOFA ([systolic blood pressure $\leq 100 \mathrm{~mm} \mathrm{Hg}$, respiratory rate $\geq 22 / \mathrm{min}$, altered mental state with Glasgow coma scale $<15$ ]: the presence of $\geq 2$ points near the onset of infection is associated with a greater risk of death or prolonged intensive care unit stay] may identify patients who are at greater risk for a poor outcome. ${ }^{146}$

\section{Cardiovascular disease}

SLE is an independent risk factor for cardiovascular disease (CVD), due to both traditional and disease-related risk factors, such as persistent disease activity, LN, presence of aPL and use of GC. ${ }^{147-149}$ Surrogate measures of atherosclerosis, such as carotid plaques, carotid intima media thickness (cIMT) and coronary artery calcium are frequently used to identify subclinical CVD in SLE ${ }^{150}$ Low-dose aspirin may be considered for primary prevention of CVD, as it may reduce the risk for incident CVD in SLE (HR 0.24 in one retrospective study). ${ }^{151} 152$ However, this has to be viewed in light of recent large studies in diabetics and elderly showing that the benefits of aspirin for primary CVD prevention are counterbalanced by the larger bleeding hazard. ${ }^{136} 153$ The value of statins in SLE has been tested in RCTs, which failed to show a clear benefit over placebo, when cIMT was used a surrogate marker for CVD. ${ }^{154} 155$ Thus, routine use of statins is not recommended for all patients but should be considered on the basis of lipid levels and the presence of other traditional risk factors. Calculation of the 10-year CVD risk using the Systematic Coronary Risk Evaluation (SCORE, https://www.escardio. org/Education/Practice-Tools/CVD-prevention-toolbox/SCORERisk-Charts) is recommended, ${ }^{156}$ although the actual risk is underestimated in patients with SLE.

Certain points to consider and the research agenda suggested by the Task Force Members are reported in box 1. These points aim to improve the design of clinical studies in order to answer clinically important questions, for which the current 'state-ofthe-art' is insufficient. In particular, data regarding the optimal duration and timing of discontinuation of therapy in both renal 


\section{Box 1 Future research agenda in SLE}

\section{Targets of therapy}

- Exploration of a universally accepted level of residual disease activity, if remission cannot be achieved.

Existing therapies and disease monitoring

- Efficacy of calcineurin inhibitor-containing treatment regimens in lupus nephritis (LN) in different racial/ethnic groups and at longer time points.

- Usefulness of measurements of drug blood levels (hydroxychloroquine [HCQ], mycophenolate mofetil and so on).

- Efficacy of quinacrine as immunomodulator in patients with HCQ-induced retinal toxicity.

- Comparative trials of conventional immunosuppressive drugs with global and organ-specific result reporting.

- Randomised trials testing lower cumulative dose glucocorticoid regimens versus conventional regimens.

- Optimal treatment regimen of rituximab: regular versus on-demand.

- Optimal duration of therapy and timing of discontinuation (renal and extrarenal disease).

- Value of repeat kidney biopsy for monitoring LN and determination of clinical versus histological response to therapy.

Pathophysiology and Biomarkers

- Susceptibility to develop systemic lupus erythematosus (SLE).

- Involvement of particular organ systems over others, multisystem versus organ-dominant disease.

- Response to specific therapeutic agents over others (pharmacogenetics, transcriptomics and so on).

Clinical trial design and new drug development

- Optimisation of clinical trial design and study endpoints to maximise probability of new drug approval in SLE.

- Handling of background medication to avoid polypharmacy and 'dilution' of positive effects of drugs under study.

- Inclusion of organ-specific endpoints and disease activity measures.

- Increase in number of adequately trained trial sites (recruitment, infrastructure and training).

- Academia versus industry-driven clinical trials.

and extrarenal disease are scarce ${ }^{157}$ for the former, recent studies support the value of a repeat kidney biopsy for the management of maintenance therapy, but more data are needed. ${ }^{158} 159$

\footnotetext{
Author affiliations

${ }^{1}$ Rheumatology and Clinical Immunology Unit, "Attikon" University Hospital, Athens, Greece

2Department of Nephrology, "G. Gennimatas" General Hospital, Athens, Greece ${ }^{3}$ Rheumatology Unit, Department of Medicine, University of Perugia, Perugia, Italy ${ }^{4}$ Division of Rheumatology, Department of Medicine III, University Medical Center \& Faculty of Medicine Carl Gustav Carus, Technical University of Dresden, Dresden, Germany

${ }^{5}$ Department of Pathology, Leiden University Medical Center, Leiden, Netherlands ${ }^{6}$ Nephrology Department and Renal Transplantation Unit, "Laikon" Hospital, National and Kapodistrian University of Athens, Medical School, Athens, Greece ${ }^{7}$ Department of Autoimmune Diseases, Hospital Clinic, Barcelona, Spain ${ }^{8}$ Rheumatology Unit, Department of Medicine, University of Padova, Padova, Italy ${ }^{9}$ Rheumatology Research Group, Institute of Inflammation and Ageing, University of Birmingham, Birmingham, UK

${ }^{10}$ Department of Medical Sciences, Section of Rheumatology, University of Ferrara, Azienda Ospedaliero-Universitaria Sant'Anna Ferrara, Ferrara, Italy

${ }^{11}$ Cliniques Universitaires Saint-Luc, Université catholique de Louvain, Brussels, Belgium

${ }^{12}$ Department of Medicine, Addenbrooke's Hospital, Cambridge, UK
}

${ }^{13}$ Cyprus League Against Rheumatism, Aglantzia, Cyprus

${ }^{14}$ University Hospital Muenster, Muenster, Germany

${ }^{15}$ Copenhagen Lupus and Vasculitis Clinic, Rheumatology and Spine Diseases Centre, Rigshospitalet, Copenhagen, Copenhagen, Denmark

${ }^{16}$ Lupus Europe, Farum, Denmark

${ }^{17}$ Nephrology Unit, Fondazione IRCCS Ca' Granda Ospedale Maggiore Policlinico, Milan, Italy

${ }^{18}$ Rheumatology Unit, Department of Clinical and Experimental Medicine, University of Pisa, Pisa, Italy

${ }^{19}$ Department of Rheumatology \& Hiller Research Unit Rheumatology, UKD, HeinrichHeine University, Düsseldorf, Germany

${ }^{20}$ Division of Rheumatology, Department of Medicine 3, Medical University of Vienna, Vienna, Austria

${ }^{21}$ Department of Medicine, Rheumatology Unit, Karolinska Institutet and Karolinska University Hospital, Stockholm, Sweden

${ }^{22}$ Department of Nephrology, 1st Faculty of Medicine and General University Hospital, Charles University, Prague, Czech Republic

${ }^{23}$ Rheumatology and Clinical Immunology, University of Brescia, Brescia, Italy

${ }^{24}$ Department of Rheumatology, Aarhus University Hospital, Aarhus, Denmark

${ }^{25}$ Department of Rheumatology and Clinical Immunology, Amsterdam University

Medical Centers, Amsterdam, Netherlands

${ }^{26}$ Department of Dermatology and Allergy, University Hospital Bonn, Bonn, Germany

${ }^{27}$ Rheumatology, Clinical Immunology and Allergy, University Hospital of Heraklion,

Heraklion, Greece

${ }^{28}$ Laboratory of Autoimmunity and Inflammation, Biomedical Research Foundation of the Academy of Athens, Athens, Greece

${ }^{29}$ Joint Academic Rheumatology Program, Medical School, National and Kapodestrian University of Athens, Athens, Greece and Medical School, University of Cyprus, Nicosia, Cyprus

Acknowledgements The committee wishes to acknowledge the support of the EULAR Standing Committee on Clinical Affairs. The committee also expresses its sincere appreciation and gratitude to the EULAR Secretariat and especially to Patrizia Jud, executive assistant, for the outstanding organisation.

Contributors AF and MK performed the systematic literature review (SLR) and AF drafted the manuscript. GB supervised the methodology of the SLR and edited the manuscript. DTB convened and supervised the project and edited the manuscript. All authors edited the manuscript and accepted its final form.

Funding AF was supported by an Articulum Fellowship and a grant from the Hellenic Society of Rheumatology during the completion of this work.

Competing interests AF reports personal fees from GSK, Abbvie, Amgen, Enorasis and Genesis Pharma, outside the submitted work. MA reports fees from advisory boards from Novartis, Pfizer, Roche. IB reports personal fees from consultant for GSK, outside the submitted work. JNB reports grants from GSK, personal fees from GSK, personal fees from Abbvie, personal fees from UCB, personal fees from Enorasis, grants from Pfizer, outside the submitted work. RC reports personal fees from GSK, personal fees from Astra Zeneca, personal fees from Rubió, outside the submitted work. DJ reports personal fees from Astra-Zeneca, Aurinia, Boehringer-Ingeleheim, Celgene, BMS, Chemocentryx, grants and personal fees from GSK, from null, outside the submitted work. AK reports grants from Biogen, grants from Galderma, grants from GlaxoSmithKline, grants from Leo Pharma, personal fees from La Roche Posay, outside the submitted work. MM reports personal fees from GSK, Lilly and UCB. MS reports grants from GSK, UCB, Abbvie, outside the submitted work. JSS reports grants from AbbVie, Astra-Zeneca, Janssen, Lilly, MSD, Novartis, Pfizer and Roche, and personal fees from AbbVie, Amgen, Astra-Zeneca, Astro, BMS, Celgene, Celltrion, Chugai, Gilead, ILTOO, Janssen, Lilly, MSD, Novartis-Sandoz, Pfizer, Roche, Samsung, Sanofi and UCB, during the conduct of the study. AT reports personal fees from UCB, Pfizer, Abbvie, BMS, Sanofi, Roche, GSK, Alpha Sigma, Lilly, Jannsen, Cellgene and Novartis, outside the submitted work. RvV reports grants from BMS, GSK, Lilly, Pfizer, UCB Pharma, personal fees from AbbVie, AstraZeneca, Biotest, Celgene, GSK Janssen, Lilly, Novartis, Pfizer, Servier, UCB, outside the submitted work. JW reports grants from GSK, grants from Incyte, personal fees from Biogen, personal fees from Leo, other from Novartis, during the conduct of the study. GB reports grants from GSK, Pfizer and personal fees from GSK, Abbvie, UCB and Enorasis, outside the submitted work. DTB reports unrestricted grant support/advisory board fees from Abbvie, BMS, Celgene, Enorasis, GSK, Pfizer, Novartis, UCB, Lilly, all deposited to the research account of the National and Kapodistrian University of Athens.

Patient consent for publication Not required.

Provenance and peer review Not commissioned; externally peer reviewed.

\section{REFERENCES}

1 Bertsias G, loannidis JPA, Boletis J, et al. EULAR recommendations for the management of systemic lupus erythematosus. Report of a task Force of the EULAR standing Committee for international clinical studies including therapeutics. Ann Rheum Dis 2008:67:195-205. 
2 Bertsias GK, loannidis JPA, Aringer M, et al. EULAR recommendations for the management of systemic lupus erythematosus with neuropsychiatric manifestations: report of a task Force of the EULAR standing Committee for clinical Affairs. Ann Rheum Dis 2010:69:2074-82.

3 Bertsias GK, Tektonidou M, Amoura Z, et al. Joint European League against rheumatism and European renal Association-European dialysis and Transplant Association (EULAR/ERA-EDTA) recommendations for the management of adult and paediatric lupus nephritis. Ann Rheum Dis 2012;71:1771-82.

4 Andreoli L, Bertsias GK, Agmon-Levin N, et al. EULAR recommendations for women's health and the management of family planning, assisted reproduction, pregnancy and menopause in patients with systemic lupus erythematosus and/or antiphospholipid syndrome. Ann Rheum Dis 2017;76:476-85.

5 Mosca M, Tani C, Aringer M, et al. European League against rheumatism recommendations for monitoring patients with systemic lupus erythematosus in clinical practice and in observational studies. Ann Rheum Dis 2010;69:1269-74.

6 Boumpas DT, Bertsias GK, Fanouriakis A. 2008-2018: a decade of recommendations for systemic lupus erythematosus. Ann Rheum Dis 2018;77:1547-8.

7 van der Heijde D, Aletaha D, Carmona L, et al. 2014 update of the EULAR standardised operating procedures for EULAR-endorsed recommendations. Ann Rheum Dis 2015;74:8-13.

8 Brouwers MC, Kho ME, Browman GP, et al. Agree Il: advancing Guideline Development, reporting and evaluation in health care. CMAJ 2010;182:E839-42.

9 Ward MM. Hospital experience and mortality in patients with systemic lupus erythematosus. Arthritis Rheum 1999;42:891-8.

10 van Vollenhoven R, Voskuyl A, Bertsias G, et al. A framework for remission in SLE: consensus findings from a large international Task Force on definitions of remission in SLE (DORIS). Ann Rheum Dis 2017;76:554-61.

11 van Vollenhoven RF, Mosca M, Bertsias G, et al. Treat-to-target in systemic lupus erythematosus: recommendations from an international Task Force. Ann Rheum Dis 2014;73:958-67.

12 Medina-Quiñones CV, Ramos-Merino L, Ruiz-Sada P, et al. Analysis of complete remission in systemic lupus erythematosus patients over a 32-year period. Arthritis Care Res 2016:68:981-7.

13 Steiman AJ, Urowitz MB, Ibañez D, et al. Prolonged clinical remission in patients with systemic lupus erythematosus. J Rheumatol 2014;41:1808-16.

14 Ugarte-Gil MF, Wojdyla D, Pons-Estel GJ, et al. Remission and low disease activity status (LDAS) protect lupus patients from damage occurrence: data from a multiethnic, multinational Latin American lupus cohort (GLADEL). Ann Rheum Dis 2017:76:2071-4

15 Urowitz MB, Feletar M, Bruce IN, et al. Prolonged remission in systemic lupus erythematosus. J Rheumatol 2005:32:1467-72.

16 Zen M, laccarino L, Gatto M, et al. Prolonged remission in Caucasian patients with SLE: prevalence and outcomes. Ann Rheum Dis 2015;74:2117-22.

17 Tsang-A-Sjoe MWP, Bultink IEM, Heslinga M, et al. Both prolonged remission and lupus low disease activity state are associated with reduced damage accrual in systemic lupus erythematosus. Rheumatology 2017:56:121-8.

18 Zen M, laccarino L, Gatto M, et al. Lupus low disease activity state is associated with a decrease in damage progression in Caucasian patients with SLE, but overlaps with remission. Ann Rheum Dis 2018;77:104-10.

19 Polachek A, Gladman DD, Su J, et al. Defining low disease activity in systemic lupus erythematosus. Arthritis Care Res 2017;69:997-1003.

20 Tselios K, Gladman DD, Touma Z, et al. Clinical remission and low disease activity have comparable outcomes over 10 years in systemic lupus erythematosus. Arthritis Care Res 2018

21 Dall'Era M, Cisternas MG, Smilek DE, et al. Predictors of long-term renal outcome in lupus nephritis trials: lessons learned from the Euro-Lupus nephritis cohort. Arthritis Rheumatol 2015:67:1305-13.

22 Touma Z, Urowitz MB, Ibañez D, et al. Time to recovery from proteinuria in patients with lupus nephritis receiving standard treatment. J Rheumatol 2014;41:688-97.

23 Mackay M, Dall'Era M, Fishbein J, et al. Establishing surrogate kidney endpoints for lupus nephritis clinical trials: development and validation of a novel approach to predict future kidney outcomes. Arthritis Rheumatol 2018.

24 Ruperto N, Hanrahan LM, Alarcón GS, et al. International consensus for a definition of disease flare in lupus. Lupus 2011;20:453-62.

25 Koutsonikoli A, Trachana M, Heidich A-B, et al. Dissecting the damage in northern Greek patients with childhood-onset systemic lupus erythematosus: a retrospective cohort study. Rheumatol Int 2015;35:1225-32.

26 Ugarte-Gil MF, Acevedo-Vásquez E, Alarcón GS, et al. The number of flares patients experience impacts on damage accrual in systemic lupus erythematosus: data from a multiethnic Latin American cohort. Ann Rheum Dis 2015;74:1019-23.

27 Franklyn K, Lau CS, Navarra SV, et al. Definition and initial validation of a lupus low disease activity state (LLDAS). Ann Rheum Dis 2016;75:1615-21.

28 Kasitanon N, Intaniwet T, Wangkaew S, et al. The clinically quiescent phase in earlydiagnosed SLE patients: inception cohort study. Rheumatology 2015;54:868-75.

29 Petri MA, van Vollenhoven RF, Buyon J, et al. Baseline predictors of systemic lupus erythematosus flares: data from the combined placebo groups in the phase III belimumab trials. Arthritis Rheum 2013;65:2143-53.
30 Steiman AJ, Gladman DD, Ibañez D, et al. Outcomes in patients with systemic lupus erythematosus with and without a prolonged serologically active clinically quiescent period. Arthritis Care Res 2012;64:511-8.

31 Weiss JE, Sison CP, Ilowite NT, et al. Flares in pediatric systemic lupus erythematosus. J Rheumatol 2007;34:1341-4.

32 Ruiz-Irastorza G, Ramos-Casals M, Brito-Zeron P, et al. Clinical efficacy and side effects of antimalarials in systemic lupus erythematosus: a systematic review. Ann Rheum Dis 2010;69:20-8.

33 Costedoat-Chalumeau N, Amoura Z, Hulot J-S, et al. Very low blood hydroxychloroquine concentration as an objective marker of poor adherence to treatment of systemic lupus erythematosus. Ann Rheum Dis 2007;66:821-4.

34 ludici M, Pantano I, Fasano S, et al. Health status and concomitant prescription of immunosuppressants are risk factors for hydroxychloroquine non-adherence in systemic lupus patients with prolonged inactive disease. Lupus 2018;27:265-72.

35 Mok CC, Penn HJ, Chan KL, et al. Hydroxychloroquine serum concentrations and flares of systemic lupus erythematosus: a longitudinal cohort analysis. Arthritis Care Res 2016:68:1295-302.

36 Melles RB, Marmor MF. The risk of toxic retinopathy in patients on long-term hydroxychloroquine therapy. JAMA Ophthalmol 2014;132:1453-60.

37 Kim J-W, Kim YY, Lee H, et al. Risk of retinal toxicity in longterm users of hydroxychloroquine. J Rheumatol 2017;44:1674-9.

38 Bruce IN, O'Keeffe AG, Farewell V, et al. Factors associated with damage accrual in patients with systemic lupus erythematosus: results from the systemic lupus international collaborating clinics (SLICC) inception cohort. Ann Rheum Dis 2015;74:1706-13

39 Chen H-L, Shen L-J, Hsu P-N, et al. Cumulative burden of Glucocorticoid-related adverse events in patients with systemic lupus erythematosus: findings from a $12-$ year longitudinal study. J Rheumatol 2018:45:83-9.

40 LSH L, Pullenayegum E, Lim L, et al. From childhood to adulthood: the trajectory of damage in patients with juvenile-onset systemic lupus erythematosus. Arthritis Care Res 2017;69:1627-35.

41 Yee C-S, Su L, Toescu V, et al. Birmingham SLE cohort: outcomes of a large inception cohort followed for up to 21 years. Rheumatology 2015;54:836-43.

42 Al Sawah S, Zhang X, Zhu B, et al. Effect of corticosteroid use by dose on the risk of developing organ damage over time in systemic lupus erythematosus--the Hopkins Lupus Cohort. Lupus Sci Med 2015;2:e000066.

43 Ruiz-Arruza I, Barbosa C, Ugarte A, et al. Comparison of high versus low-medium prednisone doses for the treatment of systemic lupus erythematosus patients with high activity at diagnosis. Autoimmun Rev 2015;14:875-9.

44 Thamer MAE, Hernan MA, Zhang Yl, et al. Prednisone, lupus activity, and permanent organ damage. J Rheumatol 2009;36:560-4

45 Buttgereit F, da Silva JAP, Boers M, et al. Standardised Nomenclature for glucocorticoid dosages and glucocorticoid treatment regimens: current questions and tentative answers in rheumatology. Ann Rheum Dis 2002;61:718-22.

46 Ruiz-Arruza I, Lozano J, Cabezas-Rodriguez I, et al. Restrictive use of oral glucocorticoids in systemic lupus erythematosus and prevention of damage without worsening long-term disease control: an observational study. Arthritis Care Res 2018:70:582-91.

47 Ruiz-Irastorza G, Ugarte A, Saint-Pastou Terrier C, et al. Repeated pulses of methylprednisolone with reduced doses of prednisone improve the outcome of class III, IV and V lupus nephritis: an observational comparative study of the Lupus-Cruces and lupus-Bordeaux cohorts. Autoimmun Rev 2017;16:826-32.

48 Singh JA, Hossain A, Kotb A, et al. Risk of serious infections with immunosuppressive drugs and glucocorticoids for lupus nephritis: a systematic review and network meta-analysis. BMC Med 2016;14.

49 Pego-Reigosa JM, Cobo-Ibánez T, Calvo-Alén J, et al. Efficacy and safety of nonbiologic immunosuppressants in the treatment of nonrenal systemic lupus erythematosus: a systematic review. Arthritis Care Res 2013;65:1775-85.

50 Sakthiswary R, Suresh E. Methotrexate in systemic lupus erythematosus: a systematic review of its efficacy. Lupus 2014;23:225-35.

51 Mok CC. Mycophenolate mofetil for non-renal manifestations of systemic lupus erythematosus: a systematic review. Scand I Rheumatol 2007;36:329-37.

52 Tselios K, Gladman DD, Su J, et al. Mycophenolate mofetil in nonrenal manifestations of systemic lupus erythematosus: an observational cohort study. J Rheumatol 2016;43:552-8.

53 Touma Z, Gladman DD, Urowitz MB, et al. Mycophenolate mofetil for induction treatment of lupus nephritis: a systematic review and metaanalysis. I Rheumatol 2011:38:69-78

54 Ordi-Ros J, Sáez-Comet L, Pérez-Conesa M, et al. Enteric-coated mycophenolate sodium versus azathioprine in patients with active systemic lupus erythematosus: a randomised clinical trial. Ann Rheum Dis 2017;76:1575-82.

55 Knight JH, Howards PP, Spencer JB, et al. Characteristics related to early secondary amenorrhoea and pregnancy among women diagnosed with systemic lupus erythematosus: an analysis using the goal study. Lupus Sci Med 2016:3:e000139.

56 Mok CC, Chan PT, To CH. Anti-Müllerian hormone and ovarian reserve in systemic lupus erythematosus. Arthritis Rheum 2013;65:206-10.

57 Tamirou F, Husson SN, Gruson D, et al. Brief report: the Euro-Lupus low-dose intravenous cyclophosphamide regimen does not impact the ovarian reserve, 
as measured by serum levels of anti-müllerian hormone. Arthritis Rheumatol 2017;69:1267-71.

58 Blumenfeld Z, Mischari 0, Schultz N, et al. Gonadotropin releasing hormone agonists may minimize cyclophosphamide associated gonadotoxicity in SLE and autoimmune diseases. Semin Arthritis Rheum 2011;41:346-52.

59 Marder W, McCune WJ, Wang L, et al. Adjunctive GnRH-a treatment attenuates depletion of ovarian reserve associated with cyclophosphamide therapy in premenopausal SLE patients. Gynecol Endocrinol 2012;28:624-7.

60 Bernatsky S, Ramsey-Goldman R, Joseph L, et al. Lymphoma risk in systemic lupus: effects of disease activity versus treatment. Ann Rheum Dis 2014;73:138-42.

$61 \mathrm{Hsu}$ CY, Lin MS, YJ S, et al. Cumulative immunosuppressant exposure is associated with diversified cancer risk among 14832 patients with systemic lupus erythematosus: a nested case-control study. Rheumatology 2017;56:620-8.

62 Cobo-lbáñez T, Loza-Santamaría E, Pego-Reigosa JM, et al. Efficacy and safety of rituximab in the treatment of non-renal systemic lupus erythematosus: a systematic review. Semin Arthritis Rheum 2014;44:175-85.

63 Merrill JT, Neuwelt CM, Wallace DJ, et al. Efficacy and safety of rituximab in moderately-to-severely active systemic lupus erythematosus: The randomized double-blind, phase II/III systemic lupus erythematosus evaluation of rituximab trial. Arthritis Rheum 2010;62:222-33.

64 Rovin BH, Furie R, Latinis K, et al. Efficacy and safety of rituximab in patients with active proliferative lupus nephritis: the Lupus nephritis assessment with rituximab study. Arthritis Rheum 2012;64:1215-26.

65 Furie R, Petri M, Zamani O, et al. A phase III, randomized, placebo-controlled study of belimumab, a monoclonal antibody that inhibits B lymphocyte stimulator, in patients with systemic lupus erythematosus. Arthritis Rheum 2011;63:3918-30.

66 Navarra SV, Guzmán RM, Gallacher AE, et al. Efficacy and safety of belimumab in patients with active systemic lupus erythematosus: a randomised, placebocontrolled, phase 3 trial. The Lancet 2011;377:721-31.

67 laccarino L, Andreoli L, Bocci EB, et al. Clinical predictors of response and discontinuation of belimumab in patients with systemic lupus erythematosus in real life setting. Results of a large, multicentric, nationwide study. J Autoimmun 2018;86:1-8.

68 Manzi S, Sánchez-Guerrero J, Merrill JT, et al. Effects of belimumab, a B lymphocyte stimulator-specific inhibitor, on disease activity across multiple organ domains in patients with systemic lupus erythematosus: combined results from two phase III trials. Ann Rheum Dis 2012;71:1833-8.

69 van Vollenhoven RF, Petri MA, Cervera R, et al. Belimumab in the treatment of systemic lupus erythematosus: high disease activity predictors of response. Ann Rheum Dis 2012;71:1343-9.

70 Díaz-Lagares C, Croca S, Sangle S, et al. Efficacy of rituximab in 164 patients with biopsy-proven lupus nephritis: pooled data from European cohorts. Autoimmun Rev 2012;11:357-64.

71 Duxbury B, Combescure C, Chizzolini C. Rituximab in systemic lupus erythematosus: an updated systematic review and meta-analysis. Lupus 2013;22:1489-503.

72 laccarino L, Bartoloni E, Carli L, et al. Efficacy and safety of off-label use of rituximab in refractory lupus: data from the Italian multicentre registry. Clin Exp Rheumatol 2015:33:449-56.

73 Ramos-Casals M, Soto MJ, Cuadrado MJ, et al. Rituximab in systemic lupus erythematosusA systematic review of off-label use in 188 cases. Lupus 2009;18:767-76

74 Olfat M, Silverman ED, Levy DM. Rituximab therapy has a rapid and durable response for refractory cytopenia in childhood-onset systemic lupus erythematosus. Lupus 2015;24:966-72.

75 Terrier B, Amoura Z, Ravaud P, et al. Safety and efficacy of rituximab in systemic lupus erythematosus: results from 136 patients from the French autoimmunity and rituximab registry. Arthritis Rheum 2010;62:2458-66.

76 Chugh S, Darvish-Kazem S, Lim W, et al. Rituximab plus standard of care for treatment of primary immune thrombocytopenia: a systematic review and metaanalysis. Lancet Haematol 2015;2:e75-81.

77 Boletis JN, Marinaki S, Skalioti C, et al. Rituximab and mycophenolate mofetil for relapsing proliferative lupus nephritis: a long-term prospective study. Nephrol Dial Transplant 2009;24:2157-60.

78 Gomez Mendez LM, Cascino MD, Garg J, et al. Peripheral blood B cell depletion after rituximab and complete response in lupus nephritis. Clin J Am Soc Nephrol 2018;13:1502-9.

79 Kuhn A, Aberer E, Bata-Csörgő Z, et al. S2k guideline for treatment of cutaneous lupus erythematosus - guided by the European Dermatology Forum (EDF) in cooperation with the European Academy of Dermatology and Venereology (EADV). J Eur Acad Dermatol Venereol 2017:31:389-404

80 Jewell ML, McCauliffe DP. Patients with cutaneous lupus erythematosus who smoke are less responsive to antimalarial treatment. J Am Acad Dermatol 2000;42:983-7

81 Kuhn A, Gensch K, Haust M, et al. Photoprotective effects of a broad-spectrum sunscreen in ultraviolet-induced cutaneous lupus erythematosus: A randomized vehicle-controlled, double-blind study. J Am Acad Dermatol 2011;64:37-48.

82 Kreuter A, Gambichler T, Breuckmann F, et al. Pimecrolimus 1\% cream for cutaneous lupus erythematosus. J Am Acad Dermatol 2004;51:407-10.
83 Kuhn A, Gensch K, Haust M, et al. Efficacy of tacrolimus $0.1 \%$ ointment in cutaneous lupus erythematosus: A multicenter, randomized, double-blind, vehicle-controlled trial. J Am Acad Dermatol 2011;65:54-64.

84 Costedoat-Chalumeau N, Dunogué B, Leroux $\mathrm{G}$, et al. A critical review of the effects of hydroxychloroquine and chloroquine on the eye. Clin Rev Allergy Immunol 2015;49:317-26.

85 Chasset F, Arnaud L, Jachiet M, et al. Changing antimalarial agents after inefficacy or intolerance in patients with cutaneous lupus erythematosus: a multicenter observational study. J Am Acad Dermatol 2018;78:107-14.

86 Chasset F, Bouaziz J-D, Costedoat-Chalumeau N, et al. Efficacy and comparison of antimalarials in cutaneous lupus erythematosus subtypes: a systematic review and meta-analysis. Br J Dermatol 2017;177:188-96.

87 Cavazzana I, Sala R, Bazzani C, et al. Treatment of lupus skin involvement with quinacrine and hydroxychloroquine. Lupus 2009;18:735-9.

88 Fruchter R, Kurtzman DJB, Patel M, et al. Characteristics and alternative treatment outcomes of Antimalarial-Refractory cutaneous lupus erythematosus. JAMA Dermatol 2017:153:937-9.

89 Wenzel J, Brahler S, Bauer R, et al. Efficacy and safety of methotrexate in recalcitrant cutaneous lupus erythematosus: results of a retrospective study in 43 patients. $\mathrm{Br} \mathrm{J}$ Dermatol 2005;153:157-62.

90 Gammon B, Hansen C, Costner MI. Efficacy of mycophenolate mofetil in antimalarialresistant cutaneous lupus erythematosus. J Am Acad Dermatol 2011;65:717-21.

91 Kreuter A, Tomi NS, Weiner SM, et al. Mycophenolate sodium for subacute cutaneous lupus erythematosus resistant to standard therapy. Br J Dermatol 2007;156:1321-7.

92 Md Yusof MY, Shaw D, El-Sherbiny YM, et al. Predicting and managing primary and secondary non-response to rituximab using B-cell biomarkers in systemic lupus erythematosus. Ann Rheum Dis 2017;76:1829-36.

93 Vital EM, Wittmann M, Edward S, et al. Brief report: responses to rituximab suggest $B$ cell-independent inflammation in cutaneous systemic lupus erythematosus. Arthritis Rheumatol 2015;67:1586-91.

94 Fernández-Nebro A, de la Fuente JLM, Carreño L, et al. Multicenter longitudinal study of B-lymphocyte depletion in refractory systemic lupus erythematosus: the LESIMAB study. Lupus 2012;21:1063-76.

95 Chasset F, Tounsi T, Cesbron E, et al. Efficacy and tolerance profile of thalidomide in cutaneous lupus erythematosus: a systematic review and meta-analysis. J Am Acad Dermatol 2018;78:342-50

96 Cortés-Hernández J, Torres-Salido M, Castro-Marrero J, et al. Thalidomide in the treatment of refractory cutaneous lupus erythematosus: prognostic factors of clinical outcome. Br J Dermatol 2012:166:616-23.

97 Bortoluzzi A, Scirè CA, Bombardieri S, et al. Development and validation of a new algorithm for Attribution of neuropsychiatric events in systemic lupus erythematosus. Rheumatology 2015;54:891-8.

98 Acr ad hoc committee on neuropsychiatric lupus nomenclature. The American College of rheumatology Nomenclature and case definitions for neuropsychiatric lupus syndromes. Arthritis Rheum 1999;42:599-608.

99 Bortoluzzi A, Fanouriakis A, Appenzeller $S$, et al. Validity of the Italian algorithm for the Attribution of neuropsychiatric events in systemic lupus erythematosus: a retrospective multicentre international diagnostic cohort study. BMJ Open 2017; 7:e015546.

100 Magro-Checa C, Zirkzee EJ, Beaart-van de Voorde LJJ, et al. Value of multidisciplinary reassessment in Attribution of neuropsychiatric events to systemic lupus erythematosus: prospective data from The Leiden NPSLE cohort. Rheumatology 2017:56:1676-83.

101 Bertsias GK, Boumpas DT. Pathogenesis, diagnosis and management of neuropsychiatric SLE manifestations. Nat Rev Rheumato/ 2010;6:358-67.

102 Bortoluzzi A, Padovan M, Farina I, et al. Therapeutic strategies in severe neuropsychiatric systemic lupus erythematosus: experience from a tertiary referral centre. Reumatismo 2012;64:350-9.

103 Dale RC, Brilot F, Duffy LV, et al. Utility and safety of rituximab in pediatric autoimmune and inflammatory CNS disease. Neurology 2014;83:142-50.

104 Fanouriakis A, Pamfil C, Sidiropoulos P, et al. Cyclophosphamide in combination with glucocorticoids for severe neuropsychiatric systemic lupus erythematosus: a retrospective, observational two-centre study. Lupus 2016:25:627-36.

105 Gupta N, Ganpati A, Mandal S, et al. Mycophenolate mofetil and deflazacort combination in neuropsychiatric lupus: a decade of experience from a tertiary care teaching hospital in southern India. Clin Rheumatol 2017;36:2273-9.

106 Narváez J, Ríos-Rodriguez V, de la Fuente D, et al. Rituximab therapy in refractory neuropsychiatric lupus: current clinical evidence. Semin Arthritis Rheum 2011;41:364-72

107 Reiner P, Galanaud D, Leroux G, et al. Long-term outcome of 32 patients with chorea and systemic lupus erythematosus or antiphospholipid antibodies. Mov Disord 2011:26:2422-7

108 Pamfil C, Fanouriakis A, Damian L, et al. EULAR recommendations for neuropsychiatric systemic lupus erythematosus vs usual care: results from two European centres. Rheumatology 2015;54:1270-8.

109 Jung J-H, Soh M-S, Ahn Y-H, et al. Thrombocytopenia in systemic lupus erythematosus: clinical manifestations, treatment, and prognosis in 230 patients. Medicine 2016;95:e2818. 
110 Serris A, Amoura Z, Canouï-Poitrine F, et al. Efficacy and safety of rituximab for systemic lupus erythematosus-associated immune cytopenias: a multicenter retrospective cohort study of 71 adults. Am J Hematol 2018;93:424-9.

111 Chaturvedi S, Arnold DM, McCrae KR. Splenectomy for immune thrombocytopenia: down but not out. Blood 2018;131:1172-82.

112 You YN, Tefferi A, Nagorney DM. Outcome of splenectomy for thrombocytopenia associated with systemic lupus erythematosus. Ann Surg 2004;240:286-92.

113 Artim-Esen B, Çene E, Şahinkaya Y, et al. Cluster analysis of autoantibodies in 852 patients with systemic lupus erythematosus from a single center. J Rheumatol 2014:41:1304-10.

114 Duarte-García A, Barr E, Magder LS, et al. Predictors of incident proteinuria among patients with SLE. Lupus Sci Med 2017:4:e000200.

115 Tang X, Huang Y, Deng W, et al. Clinical and serologic correlations and autoantibody clusters in systemic lupus erythematosus: a retrospective review of 917 patients in South China. Medicine 2010;89:62-7.

116 Houssiau FA, Vasconcelos C, D'Cruz D, et al. Immunosuppressive therapy in lupus nephritis: the Euro-Lupus nephritis trial, a randomized trial of low-dose versus highdose intravenous cyclophosphamide. Arthritis Rheum 2002;46:2121-31.

117 Houssiau FA, Vasconcelos C, D'Cruz D, et al. The 10-year follow-up data of the Euro-Lupus nephritis trial comparing low-dose and high-dose intravenous cyclophosphamide. Ann Rheum Dis 2010;69:61-4.

118 Rijnink EC, Teng YKO, Wilhelmus S, et al. Clinical and histopathologic characteristics associated with renal outcomes in lupus nephritis. Clin J Am Soc Nephrol 2017; 12:734-43.

119 Walsh M, Solomons N, Lisk L, et al. Mycophenolate mofetil or intravenous cyclophosphamide for lupus nephritis with poor kidney function: a subgroup analysis of the Aspreva lupus management study. Am J Kidney Dis 2013:61:710-5.

120 Houssiau FA, Vasconcelos C, D'Cruz D, et al. Early response to immunosuppressive therapy predicts good renal outcome in lupus nephritis: lessons from longterm followup of patients in the Euro-Lupus nephritis trial. Arthritis Rheum 2004;50:3934-40.

121 Dooley MA, Jayne D, Ginzler EM, et al. Mycophenolate versus azathioprine as maintenance therapy for lupus nephritis. N Engl J Med 2011;365:1886-95.

122 Houssiau FA, D'Cruz D, Sangle S, et al. Azathioprine versus mycophenolate mofetil for long-term immunosuppression in lupus nephritis: results from the maintain nephritis trial. Ann Rheum Dis 2010:69:2083-9.

123 Chen W, Tang X, Liu Q, et al. Short-term outcomes of induction therapy with tacrolimus versus cyclophosphamide for active lupus nephritis: a multicenter randomized clinical trial. Am J Kidney Dis 2011;57:235-44.

124 Lee YH, Lee HS, Choi SJ, et al. Efficacy and safety of tacrolimus therapy for lupus nephritis: a systematic review of clinical trials. Lupus 2011;20:636-40.

125 Miyasaka N, Kawai S, Hashimoto H. Efficacy and safety of tacrolimus for lupus nephritis: a placebo-controlled double-blind multicenter study. Mod Rheumatol 2009;19:606-15.

126 Bao H, Liu Z-H, Xie H-L, et al. Successful treatment of class V+IV lupus nephritis with multitarget therapy. J Am Soc Nephrol 2008;19:2001-10.

127 Liu Z, Zhang H, Liu Z, et al. Multitarget therapy for induction treatment of lupus nephritis: a randomized trial. Ann Intern Med 2015;162:18-26.

128 Szeto C-C, Kwan BC-H, Lai FM-M, et al. Tacrolimus for the treatment of systemic lupus erythematosus with pure class $\vee$ nephritis. Rheumatology 2008;47:1678-81.

129 Uchino A, Tsukamoto H, Nakashima $\mathrm{H}$, et al. Tacrolimus is effective for lupus nephritis patients with persistent proteinuria. Clin Exp Rheumatol 2010;28:6-12.

130 Ikeuchi H, Hiromura K, Takahashi S, et al. Efficacy and safety of multi-target therapy using a combination of tacrolimus, mycophenolate mofetil and a steroid in patients with active lupus nephritis. Mod Rheumatol 2014;24:618-25.

131 Kasitanon N, Boripatkosol P, Louthrenoo W. Response to combination of mycophenolate mofetil, cyclosporin A and corticosteroid treatment in lupus nephritis patients with persistent proteinuria. Int J Rheum Dis 2018;21:200-7.

132 Mok CC, To CH, Yu KL, et al. Combined low-dose mycophenolate mofetil and tacrolimus for lupus nephritis with suboptimal response to standard therapy: a 12-month prospective study. Lupus 2013;22:1135-41.

133 Conti F, Ceccarelli F, Perricone C, et al. The chronic damage in systemic lupus erythematosus is driven by flares, glucocorticoids and antiphospholipid antibodies: results from a monocentric cohort. Lupus 2016:25:719-26.

134 Taraborelli M, Leuenberger L, Lazzaroni MG, et al. The contribution of antiphospholipid antibodies to organ damage in systemic lupus erythematosus. Lupus 2016;25:1365-8.
135 Arnaud L, Mathian A, Ruffatti A, et al. Efficacy of aspirin for the primary prevention of thrombosis in patients with antiphospholipid antibodies: an international and collaborative meta-analysis. Autoimmun Rev 2014;13:281-91.

136 Bowman L, Mafham M, Wallendszus K, et al. Effects of aspirin for primary prevention in persons with diabetes mellitus. N Eng/ J Med 2018;379:1529-39.

137 Ridker PM. Should aspirin be used for primary prevention in the Post-Statin era? N Engl J Med 2018;379:1572-4.

138 Pengo V, Ruffatti A, Legnani C, et al. Clinical course of high-risk patients diagnosed with antiphospholipid syndrome. J Thromb Haemost 2010;8:237-42.

139 Pengo V, Denas G, Zoppellaro G, et al. Rivaroxaban vs warfarin in high-risk patients with antiphospholipid syndrome. Blood 2018;132:1365-71.

140 Chen D, Xie J, Chen H, et al. Infection in southern Chinese patients with systemic lupus erythematosus: spectrum, drug resistance, outcomes, and risk factors. J Rheumatol 2016;43:1650-6.

141 Rúa-Figueroa Î́igo, López-Longo J, Galindo-Izquierdo M, et al. Incidence, associated factors and clinical impact of severe infections in a large, multicentric cohort of patients with systemic lupus erythematosus. Semin Arthritis Rheum 2017:47:38-45.

142 Costa-Reis P, Nativ S, Isgro J, et al. Major infections in a cohort of 120 patients with juvenile-onset systemic lupus erythematosus. Clin Immunol 2013;149:442-9.

143 Hiraki LT, Feldman CH, Marty FM, et al. Serious infection rates among children with systemic lupus erythematosus enrolled in Medicaid. Arthritis Care Res 2017:69:1620-6.

144 Elkayam Oet al. Update of EULAR recommendations for vaccination of patients with autoimmune inflammatory rheumatic diseases. Ann Rheum Dis 2018;77.

145 van Assen S, Agmon-Levin N, Elkayam O, et al. EULAR recommendations for vaccination in adult patients with autoimmune inflammatory rheumatic diseases. Ann Rheum Dis 2011;70:414-22.

146 Seymour CW, Liu VX, Iwashyna TJ, et al. Assessment of clinical criteria for sepsis: for the third International consensus definitions for sepsis and septic shock (Sepsis-3). JAMA 2016;315:762-74.

147 Ballocca F, D'Ascenzo F, Moretti C, et al. Predictors of cardiovascular events in patients with systemic lupus erythematosus (SLE): a systematic review and metaanalysis. Eur J Prev Cardiol 2015;22:1435-41.

148 Magder LS, Petri M. Incidence of and risk factors for adverse cardiovascular events among patients with systemic lupus erythematosus. Am J Epidemiol 2012;176:708-19.

149 Wu G-C, Liu H-R, Leng R-X, et al. Subclinical atherosclerosis in patients with systemic lupus erythematosus: a systemic review and meta-analysis. Autoimmun Rev 2016:15:22-37.

150 Gustafsson JT, Svenungsson E. Definitions of and contributions to cardiovascular disease in systemic lupus erythematosus. Autoimmunity 2014;47:67-76.

151 Fasano S, Pierro L, Pantano I, et al. Longterm hydroxychloroquine therapy and low-dose aspirin may have an additive effectiveness in the primary prevention of cardiovascular events in patients with systemic lupus erythematosus. J Rheumatol 2017:44:1032-8

152 Iudici M, Fasano S, Gabriele Falcone L, et al. Low-dose aspirin as primary prophylaxis for cardiovascular events in systemic lupus erythematosus: a long-term retrospective cohort study. Rheumatology 2016;55:1623-30.

153 Gaziano JM, Brotons C, Coppolecchia R, et al. Use of aspirin to reduce risk of initial vascular events in patients at moderate risk of cardiovascular disease (ARRIVE): a randomised, double-blind, placebo-controlled trial. Lancet 2018;392:1036-46.

154 Petri MA, Kiani AN, Post W, et al. Lupus atherosclerosis prevention study (LAPS). Ann Rheum Dis 2011;70:760-5.

155 Schanberg LE, Sandborg C, Barnhart HX, et al. Use of atorvastatin in systemic lupus erythematosus in children and adolescents. Arthritis Rheum 2012;64:285-96.

156 Piepoli MF, Hoes AW, Agewall S, et al. 2016 European Guidelines on cardiovascular disease prevention in clinical practice: The Sixth Joint Task Force of the European Society of Cardiology and Other Societies on Cardiovascular Disease Prevention in Clinical Practice (constituted by representatives of 10 societies and by invited experts)Developed with the special contribution of the European Association for Cardiovascular Prevention \& Rehabilitation (EACPR). Eur Heart J 2016;37:2315-81.

157 Moroni G, Raffiotta F, Ponticelli C. Remission and withdrawal of therapy in lupus nephritis. J Nephrol 2016;29:559-65.

158 Piñeiro GJ, Arrizabalaga P, Solé M, et al. Repeated Renal Biopsy - A Predictive Tool to Assess the Probability of Renal Flare in Lupus Nephritis. Am J Nephrol 2016;44:439-46.

159 De Rosa M, Azzato F, Toblli JE, et al. A prospective observational cohort study highlights Kidney biopsy findings of lupus nephritis patients in remission who flare following withdrawal of maintenance therapy. Kidney Int 2018;94:788-94. 